\title{
Measurement of Elastic Parameters of Lithium Hydroxylammonium Sulphate Single Crystal, by Ultrasonic Pulse Echo Overlap Technique
}

\author{
George Varughese ${ }^{1}$, Santhosh Kumar ${ }^{2}$ \\ ${ }^{1}$ Department of Physics, Catholicate College, Pathanamthitta, India \\ ${ }^{2}$ SPAP, Mahatma Gandh University, Kottayam, India \\ Email: ${ }^{*}$ gvushakoppara@yahoo.co.in
}

Received 25 July 2014; revised 16 August 2014; accepted 12 September 2014

Copyright (C) 2014 by authors and Scientific Research Publishing Inc.

This work is licensed under the Creative Commons Attribution International License (CC BY).

http://creativecommons.org/licenses/by/4.0/

(c) (i) Open Access

\section{Abstract}

Ultrasonics is the most established and precise technique to determine the elastic parameters of materials. Elastic constants are important parameters of a crystal which provide valuable information about the bonding characteristic between adjacent atomic planes and the anisotropic character of the bonding and structural ability. Second order elastic constants can be measured by measuring the velocity of the ultrasonic pulses of different polarization along different symmetry directions. Elastic Constants of Lithium Hydroxylammonium Sulphate [LHAS] single crystal by ultrasonic Pulse Echo Overlap [PEO] technique are reported for the first time. Large single crystals of LHAS of size $[26 \times 26 \times 10] \mathrm{mm}^{3}$ have been grown from supersaturated aqueous solution of the salt by slow evaporation technique over a period of 40 - 45 days at $305 \mathrm{~K}$. Absolute velocities at room temperature ( $303 \mathrm{~K}$ ) have been measured for the selected direction and modes with McSkimin $\Delta t$ criterion. The anisotropy in the elastic properties of LHAS is well studied by measuring ultrasonic velocity in the crystal in certain specified crystallographic directions. The elastic stiffness constants, $C_{11}, C_{33}, C_{44}, C_{55}$ and $C_{66}$, and Acoustic impedance constants and Rao's constants in specified directions are evaluated.

\section{Keywords}

Inorganic Compounds, Crystal Growth, Ultrasonic Velocity, Elastic Constants

\footnotetext{
${ }^{*}$ Corresponding author.
}

How to cite this paper: Varughese, G. and Kumar, S. (2014) Measurement of Elastic Parameters of Lithium Hydroxylammonium Sulphate Single Crystal, by Ultrasonic Pulse Echo Overlap Technique. Open Journal of Acoustics, 4, 138-144. 


\section{Introduction}

The second order elastic stiffness constants play an important role in determining the strength of materials, provide valuable information about the bonding characteristic between adjacent atomic planes and the anisotropic character of the bonding and structural ability. The elastic behavior of an asymmetric crystal is determined by 21 independent elastic constants. The number of independent elastic constants will vary with symmetry of the crystal. It is 9 for orthorhombic crystal and they are $C_{11}, C_{22}, C_{33}, C_{44}, C_{55}, C_{66}, C_{12}, C_{13}$, and $C_{23}$. Ultrasonics is the most established technique to determine the elastic moduli of both static and dynamic properties. Measurements of the elastic constants of a crystal as a function of temperature enable one to locate phase transition points. Second order elastic constants can be measured by measuring the velocity of the ultrasonic pulses of different polarization along different symmetry directions. Different techniques have been developed for precise measurement of velocity. Of these Pulse Echo Overlap (PEO) technique is the most accurate and precise one. In Lithium Hydroxylammonium Sulphate [ $\mathrm{LiNH}_{3} \mathrm{OHSO}_{4}$ ] crystal, no work has been reported on elastic properties.. In the present study Elastic constants are measured, by ultrasonic Pulse Echo Overlap [PEO] technique for the first time. It crystallizes in the orthorhombic symmetry with space group Pbca with lattice parameters are reported to be $a=18.461, b=7.267$ and $c=6.695 \AA$ [1]. The unit cell comprised of eight molecules. The structure of the crystal was reported in the literature [2] [3]. The refined crystal structure of the LHAS crystal was also reported [4]. Figure 1 shows distribution of atoms in the unit cell of Lithium Hydroxylammonium Sulphate [LHAS] crystal. Infrared and Raman spectra of LHAS and deuterated LHAS was reported [5]. Bands were assigned on the basis of $\mathrm{SO}_{4}, \mathrm{NH}_{3}$ and $\mathrm{OH}$ vibrations. The symmetric stretching mode in the deuterated compound is found to be at higher frequencies, indicating the existence of strong hydrogen bonds in LHAS. The $\mathrm{SO}_{4}$ ion is distorted in the crystal. The general data of LHAS shows that the crystal decomposes above $110^{\circ} \mathrm{C}$ $(380 \mathrm{~K})$ [5]. The aim of this work is to measure absolute ultrasonic wave velocities at $303 \mathrm{~K}$ for the selected direction with McSkimin $\Delta t$ criterion. The anisotropy in the elastic properties is well studied by measuring ultrasonic velocity in the crystal in certain specified crystallographic directions. The elastic constants, compliance constants, Acoustic impedance, and Poisson's ratio are evaluated. The polar plots of phase velocity, slowness, Young's modulus, linear compressibility in the [110], [101] and [011] planes reveal the anisotropy.

\section{Material and Methods}

\subsection{Crystal Growth}

Single crystal of LHAS have been grown by slow evaporation method from an aqueous solution of Hydroxylamine Sulphate $\left(\mathrm{NH}_{3} \mathrm{OH}\right)_{2} \mathrm{SO}_{4}$ and Lithium Sulphate $\left(\mathrm{Li}_{2} \mathrm{SO}_{4}\right)$ in stoichiometric quantities at $45^{\circ} \mathrm{C}$. Figure 2 and Figure 3 depict morphology and photograph of solution grown crystal. There are difficulties in growing the crystal. Spurious bubbles are forming in the growing medium. These bubbles may incorporate in the crystal and may cause defect in the growing crystal. By adjusting the growth temperature this can be minimized and the suitable temperature was found to be $45^{\circ} \mathrm{C}$. Increasing the speed of the solution stirrer also minimize the incorporation of the spurious air bubbles into the crystal. Another difficulty is the tendency of these crystals to grow in thin plates. But the thickness of the crystal can be increased by using a cut samples as a seed crystal. Also recrystallization by several times improves the thickness to a suitable size. Taking these factors, the growth can be controlled and single crystal of size $[26 \times 26 \times 10] \mathrm{mm}^{3}$ was obtained after 40 days. The density of the crystal was measured using Archimedes principle and was found to be $2.002 \mathrm{gm} / \mathrm{cm}^{3}$.

The crystallographic axes are identified using the software J crystal (stereographic net) and Shape. The interfacial angles are measured using a contact goniometer. The measured angles were well in agreement with the computed values. By knowing the lattice parameters and crystal system one can construct a stereographic plot by using the computer program "Jcrystal". The natural faces of the sample have been identified by comparing the computed value and the measured value. The grown crystal is cut into required thickness along different crystallographic directions using a slow speed Diamond Wheel Saw. An interesting feature was noted while cutting the crystal was, that the crystal could be easily peeled along the c-direction even with a sharp blade. This is because of the crystal have a cleavage plane perpendicular to $c$-axis. Thus cutting the crystal along $b$-direction is difficult; and hence measurement along that direction was forced to avoid. Also care should be taken while cutting the crystal in a-direction. Bulk samples have been cut using a slow speed diamond wheel saw (model-650, South Bay technology, USA). The diamond saw consists of a thin metal disc with micro sized diamond powder embedded on the outer edge. The blade fixed to a rotation mechanism is driven by a speed controlled motor. The 


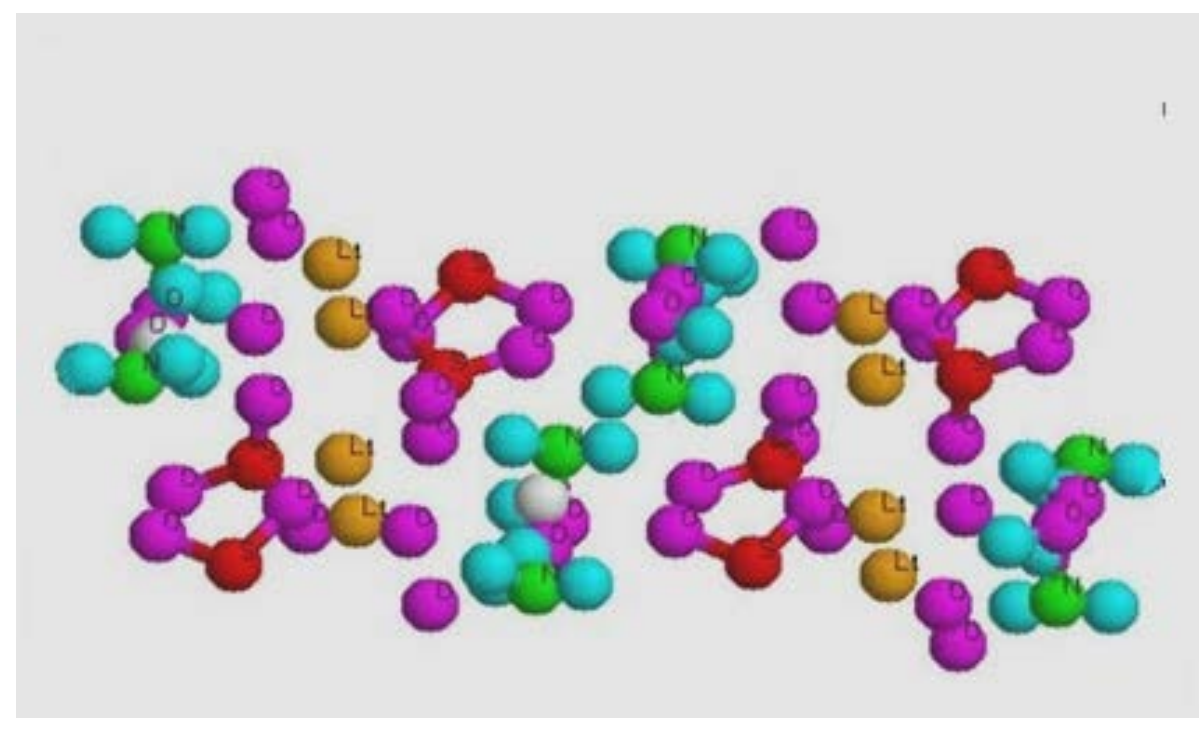

Figure 1. Distribution of atoms in the unit cell of of LHAS crystal in the $a$-c plane.

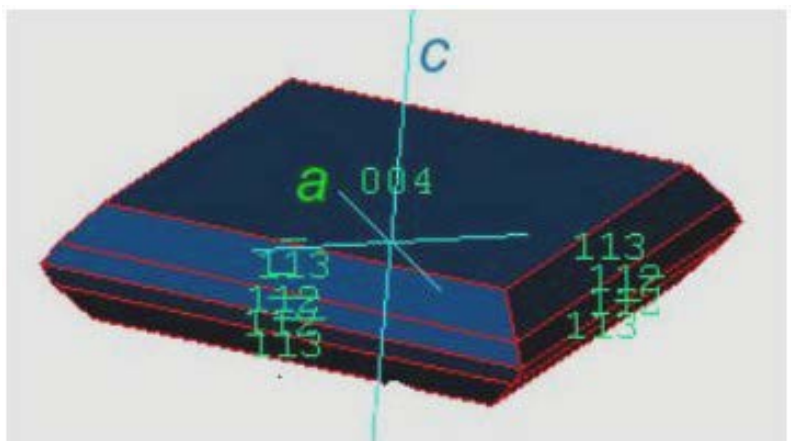

Figure 2. Morphology of the LHAS crystal.

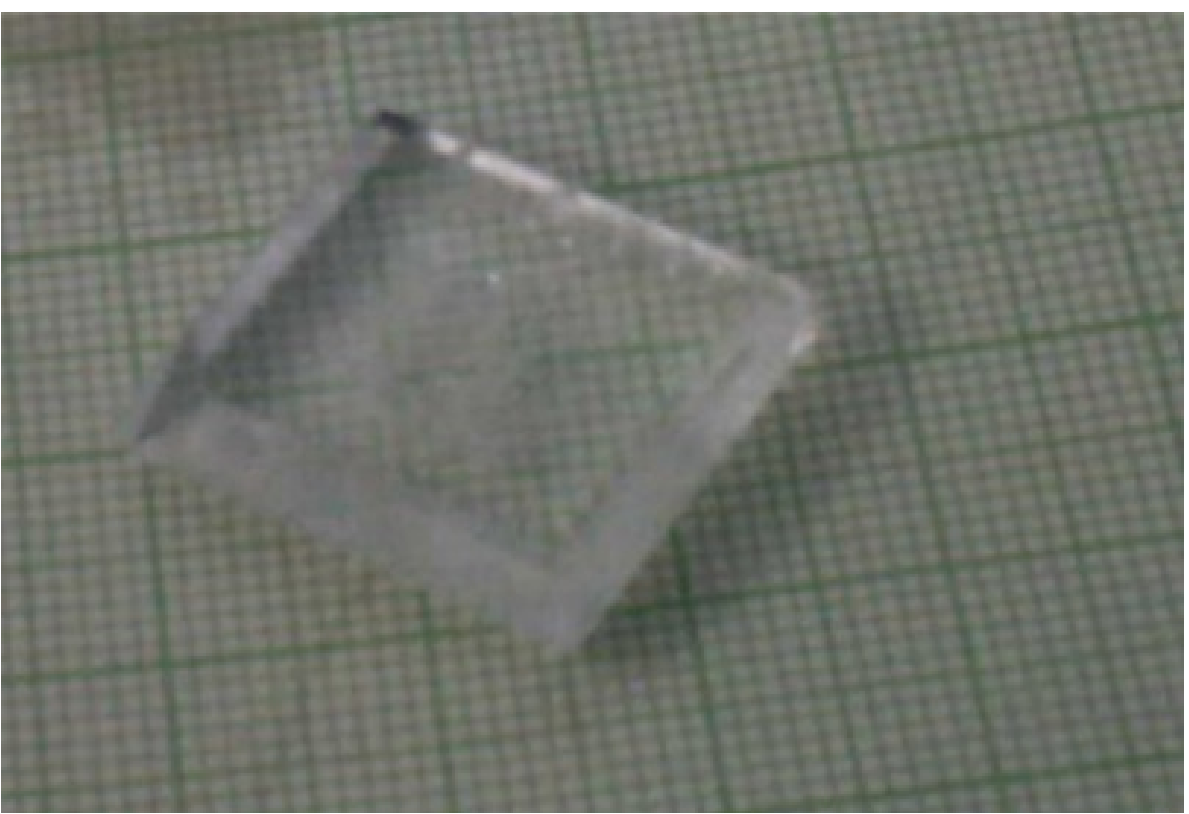

Figure 3. Photograph of the grown LHAS crystal. 
crystal to be cut is glued to a precision movable arm with a goniometer and counter weight. Once the directions are carefully adjusted with respect to the blade, the arm can be lowered so that the crystal rests on the rotating blade edge. The blade is continuously cooled and cleaned by a coolant, which is kept below the tray. One advantage of this diamond wheel saw is that samples can be cut easily to have parallel faces. This is very important for ultrasonic work because the non-parallelism will bring in a non-exponentially decaying echo pattern and thereby additional errors in velocity measurements. Samples with pairs of parallel planes perpendicular to [100] and [001] directions have been prepared for ultrasonic wave velocity measurements. All cuttings are made very accurately. The error due to disorientation is below $\pm 0.5^{\circ}$. The edges of the samples have been polished carefully using cerium oxide powder to optical reflection level so as to ensure proper bonding of the transducer to the sample surface. Polishing of the sample and cleaning of the transducer are very important for successful bonding. To make the bond thin, the transducer has to be held pressed to the sample under spring action.

\subsection{Measurements of Elastic Constants}

The elements of determinantal equation are defined by elastic constants and the direction cosines of the direction of propagation [6] [7]. Non zero elastic constants are shown in the determinant.

$$
C_{i j}=\left|\begin{array}{cccccc}
C_{11} & C_{12} & C_{13} & 0 & 0 & 0 \\
C_{12} & C_{22} & C_{23} & 0 & 0 & 0 \\
C_{13} & C_{23} & C_{33} & 0 & 0 & 0 \\
0 & 0 & 0 & C_{44} & 0 & 0 \\
0 & 0 & 0 & 0 & C_{55} & 0 \\
0 & 0 & 0 & 0 & 0 & C_{66}
\end{array}\right|
$$

LHAS being an Orthorhombic crystal, has the following nine second order elastic stiffness constants $C_{11}$, $C_{22}, C_{33}, C_{44}, C_{55}, C_{66}, C_{12}, C_{13}$ and $C_{23}$. The diagonal elastic constants $C_{11}, C_{22}, C_{33}, C_{44}, C_{55}$ and $C_{66}$ have direct relationship with the ultrasonic mode velocity given by $C_{i j}=\rho V^{2}$. For propagation in $x$ direction,

$$
\rho v_{0}^{2}=C_{11}, \quad \rho v_{1}^{2}=C_{66}, \quad \rho v_{2}^{2}=C_{55}
$$

Then the three pure modes will be, $v_{0}$ longitudinal, $v_{1}$ transverse with $y$ polarization and $v_{2}$ transverse with $z$ polarization. For propagation in $y$-direction,

$$
\rho v_{0}^{2}=C_{66}, \quad \rho v_{1}^{2}=C_{22}, \quad \rho v_{2}^{2}=C_{44}
$$

$v_{0}$ is transverse with $x$-polarization $v_{1}$ is longitudinal $v_{2}$ is transverse with $z$-polarization. For propagation in $z$ direction

$$
\rho v_{0}^{2}=C_{55}, \quad \rho v_{1}^{2}=C_{44}, \quad \rho v_{2}^{2}=C_{33}
$$

These are also pure modes with $v_{0}$ transverse with $x$-polarization, $v_{1}$ transverse with $y$-polarization and $v_{2}$ longitudinal. The elastic constant $C_{12}$ can be calculated by measuring the velocity perpendicular $a-b$ plane. Here the angle is measured from $a$-axis. Then

$$
C_{12}=f_{a b}=\left\{\frac{1}{c^{2} s^{2}}\left[\left(s^{2} C_{11}+s^{2} C_{66}-\rho v^{2}\right)\left(c^{2} C_{66}+s^{2} C_{22}-\rho v^{2}\right)\right]\right\}^{1 / 2}-C_{66}
$$

The elastic constant $C_{23}$ is measured by propagating the sound wave with the velocity normal to the $b-c$ plane. The angle is measured from $b$-axis. Then

$$
C_{23}=f_{b c}=\left\{\frac{1}{c^{2} s^{2}}\left[\left(c^{2} C_{22}+s^{2} C_{44}-\rho v^{2}\right)\left(c^{2} C_{44}+s^{2} C_{33}-\rho v^{2}\right)\right]\right\}^{1 / 2}-C_{44}
$$

The elastic constant $C_{13}$ can be measured by propagating the waves perpendicular to $a$-c plane where angle $\theta$ is measured from $c$-axis. 


$$
C_{13}=f_{a c}=\left\{\frac{1}{c^{2} s^{2}}\left[\left(s^{2} C_{11}+c^{2} C_{55}-\rho v^{2}\right)\left(s^{2} C_{55}+c^{2} C_{33}-\rho v^{2}\right)\right]\right\}^{1 / 2}-C_{55}
$$

where $s=\sin \theta \quad c=\cos \theta$ and $\theta$ is the angle of rotation for respective axes.

Acoustic Impedance constants [11] of the crystal in specified direction are given by

$$
Z_{i j}=\rho v_{i j}
$$

where $\rho$ is the density of the sample (=2002 gm/cc. for LHAS) and $v$ is the velocity in specified directions. Rao's Constants (molar velocity) of the crystal [11] in specified directions are given by

$$
R_{i j}=m / \rho\left(v_{i j}\right)^{1 / 3}
$$

where $m$ is the molar mass and $\rho$ density of material and $v$, the ultrasonic velocity in the crystal along specified directions.

\subsection{Ultrasonic Velocity Measurements}

The ultrasonic velocities are measured using the PEO technique [9]. The details of measurement technique are by Papadakis [10]. A MATEC model 7700 pulse modulator and receiver system with its associated subunits has been used for the velocity measurements. $X$-Cut transducers of resonant frequency $10 \mathrm{MHz}$ and $6 \mathrm{~mm}$ in diameter are used for the measurement of longitudinal velocity and $Y$-Cut transducer of resonant frequency 10 $\mathrm{MHz}$ and $6 \mathrm{~mm}$ diameter are used for the measurement of transverse velocity. Large number of clear echoes indicated that the grown samples are free from defects. The same transducer has been used to detect the echoes generated by successive reflection of the waves from the rear end of the sample. Absolute velocities at room temperature (303 K) have been measured for the selected direction and modes [12]. The McSkimin $\Delta t$ criterion [13]-[17] has been applied to correct the phase lag introduced by the bonding medium on the RF echoes.

\section{Results and Discussions}

Of the 18 propagation modes, velocity measurements of 12 modes are sufficient to evaluate all the six independent second-order elastic constants and three dependent constants with cross checks possible using the remaining modes. Whereas the present studies have been reported 5 elastic constants. Considering all experimental uncertainties, the absolute accuracy of elastic constant value is estimated to be better than $0.2 \%$. In all velocity measurements, the correct overlap identification is made and McSkimin $\Delta t$ criterion for bond correction has been applied using computer programme [18]. By measuring ultrasonic velocity in the LHAS crystal in certain specified crystallographic directions, the anisotropy of elastic properties of the crystal is studied and the elastic stiffness constants, and acoustic impedance are evaluated. Of the six independent elastic constants we could be able to measure 5 elastic constants.

The diagonal elastic constant $C_{22}$ could not be measured due to the existence of cleavage plane along $c$ direction and hence difficult to prepare sample with $a-b, a-c$, and $b-c$ planes. The values of the 5 elastic constants are presented in Table 1. The acoustic impedance constants and Rao's constants are presented in Table 2 and

\begin{tabular}{|c|c|c|c|c|c|c|}
\hline Sl.No & Mode & $\begin{array}{l}\text { Direction of } \\
\text { propagation }\end{array}$ & $\begin{array}{l}\text { Direction of } \\
\text { polarization }\end{array}$ & $\begin{array}{l}\text { Velocity } \\
\text { measured } V(\mathrm{~m} / \mathrm{s})\end{array}$ & $\begin{array}{c}\text { Elastic constant } \\
\qquad C_{i j}(\mathrm{GPa})\end{array}$ & $\begin{array}{l}V-C_{i j} \\
\text { relationship }\end{array}$ \\
\hline 1 & $\mathrm{~L}$ & {$[100]$} & [100] & $v_{1}=3142 \pm 4$ & $19.76 \pm 0.07$ & $C_{11}=\rho v_{1}^{2}$ \\
\hline 2 & $\mathrm{~L}$ & [001] & {$[001]$} & $v_{3}=2917 \pm 4$ & $17.03 \pm 0.07$ & $C_{33}=\rho v_{3}^{2}$ \\
\hline 3 & $\mathrm{~T}$ & [001] & {$[010]$} & $v_{4}=2247 \pm 3$ & $10.10 \pm 0.03$ & $C_{44}=\rho v_{4}^{2}$ \\
\hline 4 & $\mathrm{~T}$ & {$[001]$} & {$[100]$} & $v_{5}=2424 \pm 3$ & $11.72 \pm 0.03$ & $C_{55}=\rho v_{5}^{2}$ \\
\hline 5 & $\mathrm{~T}$ & [100] & [010] & $v_{6}=2542 \pm 3$ & $12.93 \pm 0.04$ & $C_{66}=\rho v_{6}^{2}$ \\
\hline
\end{tabular}
Table 3 respectively. Here compliance constants and Poisson's ratios are not evaluated since Compliance con-

Table 1. Measured velocities and Elastic constants of LHAS crystal at $303 \mathrm{~K}$.

The abbreviation used have the following meaning: L-Longitudinal; T-Transverse. Then $v$ is the velocity of propagation of respective mode and $\rho$ is the density of the sample $=2002 \mathrm{~kg} / \mathrm{m}^{3}$. and molar mass $0.137 \mathrm{~kg}$ for LHAS crystal. 
Table 2. Measured velocities and Acoustic impedance constants of LHAS crystal at $303 \mathrm{~K}$.

\begin{tabular}{|c|c|c|c|c|c|c|}
\hline Sl.No & Mode & $\begin{array}{l}\text { Direction of } \\
\text { propagation }\end{array}$ & $\begin{array}{l}\text { Direction of } \\
\text { polarization }\end{array}$ & $\begin{array}{c}\text { Velocity } \\
\text { measured } v(\mathrm{~m} / \mathrm{s})\end{array}$ & $\begin{array}{l}\text { Acoustic impedance } \\
106 \mathrm{~kg} / \mathrm{m}^{2} / \mathrm{s}\end{array}$ & $\begin{array}{l}\qquad V-Z_{i j} \\
\text { relationship }\end{array}$ \\
\hline 1 & $\mathrm{~L}$ & [100] & [100] & $v_{1}=3142 \pm 4$ & $6290 \pm 0.07$ & $Z_{11}=\rho v_{1}$ \\
\hline 2 & $\mathrm{~L}$ & [001] & [001] & $v_{3}=2917 \pm 4$ & $5839 \pm 0.07$ & $Z_{33}=\rho v_{3}$ \\
\hline 3 & $\mathrm{~T}$ & [001] & [010] & $v_{4}=2247 \pm 3$ & $4498 \pm 0.03$ & $Z_{44}=\rho v_{4}$ \\
\hline 4 & $\mathrm{~T}$ & [001] & [100] & $v_{5}=2424 \pm 3$ & $4852 \pm 0.03$ & $Z_{55}=\rho v_{5}$ \\
\hline 5 & $\mathrm{~T}$ & [100] & [010] & $v_{6}=2542 \pm 3$ & $5089 \pm 0.04$ & $Z_{66}=\rho v_{6}$ \\
\hline
\end{tabular}

Table 3. Measured velocities and Rao’s constants (Molar velocity) of LHAS crystal at $303 \mathrm{~K}$.

\begin{tabular}{|c|c|c|c|c|c|c|}
\hline Sl.No & Mode & $\begin{array}{l}\text { Direction of } \\
\text { propagation }\end{array}$ & $\begin{array}{l}\text { Direction of } \\
\text { polarization }\end{array}$ & $\begin{array}{c}\text { Velocity } \\
\text { measured } v(\mathrm{~m} / \mathrm{s})\end{array}$ & $\begin{array}{c}\text { Rao's constant } \\
10-6 \mathrm{~m}^{3} / \\
\mathrm{mol} /(\mathrm{m} / \mathrm{s}) 1 / 3\end{array}$ & $\begin{array}{l}\qquad V-R_{i j} \\
\text { relationship }\end{array}$ \\
\hline 1 & $\mathrm{~L}$ & {$[100]$} & {$[100]$} & $v_{1}=3142 \pm 4$ & $1002 \pm 0.07$ & $R_{11}=m / \rho\left(v_{1}\right)^{1 / 3}$ \\
\hline 2 & $\mathrm{~L}$ & [001] & {$[001]$} & $v_{3}=2917 \pm 4$ & $977 \pm 0.07$ & $R_{33}=m / \rho\left(v_{3}\right)^{1 / 3}$ \\
\hline 3 & $\mathrm{~T}$ & [001] & [010] & $v_{4}=2247 \pm 3$ & $896 \pm 0.03$ & $R_{44}=m / \rho\left(v_{4}\right)^{1 / 3}$ \\
\hline 4 & $\mathrm{~T}$ & {$[001]$} & {$[100]$} & $v_{5}=2424 \pm 3$ & $919 \pm 0.03$ & $R_{55}=m / \rho\left(v_{5}\right)^{1 / 3}$ \\
\hline 5 & $\mathrm{~T}$ & [100] & [010] & $v_{6}=2542 \pm 3$ & $934 \pm 0.04$ & $R_{66}=m / \rho\left(v_{6}\right)^{1 / 3}$ \\
\hline
\end{tabular}

stants are the components obtained from the inverse matrix of elastic constants.

\section{Conclusion}

LHAS crystal of large size has been grown using slow evaporation solution growth technique. PEO technique has been successfully implemented for evaluating 5 elastic constants $C_{11}, C_{33}, C_{44}, C_{55}$, and $C_{66}$ and explained the anisotropy in the elastic properties of the crystal. The diagonal constant $C_{22}$ and off diagonal constants $C_{12}$, $C_{13}, C_{23}$ could not be measured due to presence of cleavage plane along $c$ direction. The temperature variationsof elastic constants were not carried out due to bonding problems. Acoustic impedance constants and Rao's constants (molar velocity) are also evaluated along specified directions. From the data it is found that $C_{11}$ and $C_{44}$ have maximum (19.76 GPa) and minimum (10.10 GPa) value respectively.

\section{References}

[1] Vilminot, S., Anderson, M.R. and Brown, D. (1973) The Crystal Structure of Lithium Hydroxylammonium Sulphate. Acta Crystallographica, B29, 2628. http://dx.doi.org/10.1107/S056774087300720X

[2] Brown, I.D. (1964) The Crystal Structure of Lithium Hydrazinium Sulfate. Acta Crystallographica, 17, 654-660. http://dx.doi.org/10.1107/S0365110X64001591

[3] Anderson, M.R., Brown, I.D. and Vilminot, S. (1973) The Crystal Structure of Lithium Hydrazinium Fluoroberyllate. Acta Crystallographica, B29, 2625-2627. http://dx.doi.org/10.1107/S0567740873007193

[4] Chung, S.J. and Hahn, T. (1972) Tetrahedral-Framework Structures of $\mathrm{NH}_{4} \mathrm{LiBeF}_{4}$ and $\mathrm{CsLiBeF}_{4}$. Materials Research Bulletin, 7, 1209-1217. http://dx.doi.org/10.1016/0025-5408(72)90100-6

[5] Mahadevan Pillai, V.P. and Pradeep, T. (1992) Vibrational Spectra of $\mathrm{LiNH}_{3} \mathrm{OHSO}_{4}$ and $\mathrm{LiND}_{3} \mathrm{ODSO}_{4}$. Journal of Raman Spectroscopy, 23, 235-237. http://dx.doi.org/10.1002/jrs.1250230408

[6] JCPDS Card No: 29-792 (1976).

[7] Truell, R., Elbaum, C. and Chick, B.B. (1969) Ultrasonic Methods in Solid State Physics, Academic Press, New York, 370. http://dx.doi.org/10.1016/B978-1-4832-3318-5.50003-1

[8] Nye, N.F. (1957) Physical Properties of Crystals. Oxford Univ. Press, London, 145.

http://www.mediafire.com/?3wx2faaheaepkyx 
[9] Papadakis, E.P. (1967) Ultrasonic Pulse Velocity by the Pulse-Echo Overlap Method Incorporating Diffraction Phase Correlation. The Journal of the Acoustical Society of America, 42, 1045.

[10] Papadakis, E.P. (1976) Ultrasonic Velocity and Attenuation: Measurement Methods with Scientific and Industrial Applications. In: Mason, W.P. and Thurston, R.N., Eds., Physical Acoustics: Principles and Methods, Academic Press, New York, 227-374.

[11] Ali, A. and Nain, A.K. (1996) Ultrasonic Study of Molecular Interactions in N, N-Dimethylacetamide+ Ethanol Binary Mixtures at Various Temperatures. Acoustics Letters, 19, 181-187.

[12] Godfrey, L., Philip, J. and Sebastian, M.T. (1994) Elastic Constants and High-Temperature Elastic Anomalies near 425 K in Lithium Hydrazinium Sulfate. Journal of Applied Physics, 75, 2393.

[13] May Jr., J.E. (1958) Circuit Theory; Ultrasonic engineering. IRE National Convention Record, 6, 134-142.

[14] McSkimin, H.J. (1961) Pulse Superposition Method for Measuring Ultrasonic Wave Velocities in Solids. The Journal of the Acoustical Society of America, 33, 12. http://dx.doi.org/10.1121/1.1908386

[15] McSkimin, H.J. and Andreatch, P. (1962) Analysis of the Pulse Superposition Method for Measuring Ultrasonic Wave Velocities as a Function of Temperature and Pressure. The Journal of the Acoustical Society of America, 34, 609. http://dx.doi.org/10.1121/1.1918175

[16] McSkimin, H.J. (1964) Ultrasonic Methods for Measuring the Mechanical Properties of Liquids and Solids. In: Mason, W.P., Ed., Physical Acoustics, Academic Press, New York, 271.

[17] Godfrey, L. and Philip, J. (1995) Numerical Technique for Bond Correction in Ultrasonic Measurements. Acoustics Letters, 19, 111-114. 
Scientific Research Publishing (SCIRP) is one of the largest Open Access journal publishers. It is currently publishing more than 200 open access, online, peer-reviewed journals covering a wide range of academic disciplines. SCIRP serves the worldwide academic communities and contributes to the progress and application of science with its publication.

Other selected journals from SCIRP are listed as below. Submit your manuscript to us via either submit@scirp.org or Online Submission Portal.
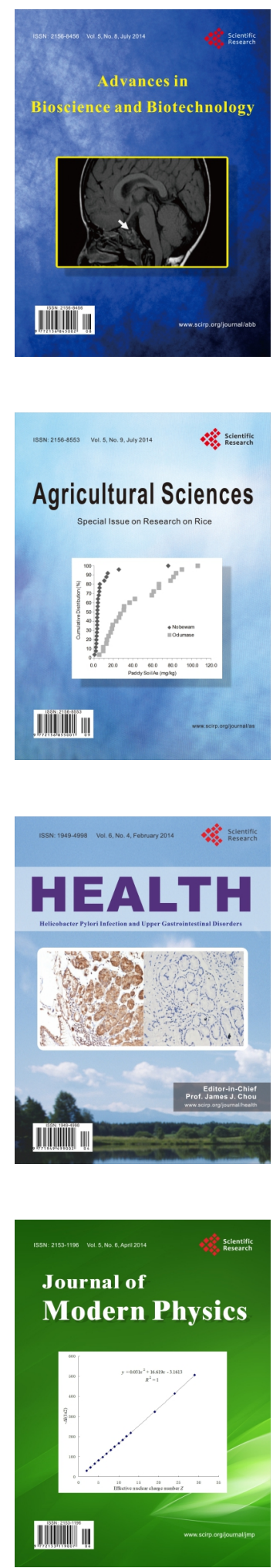
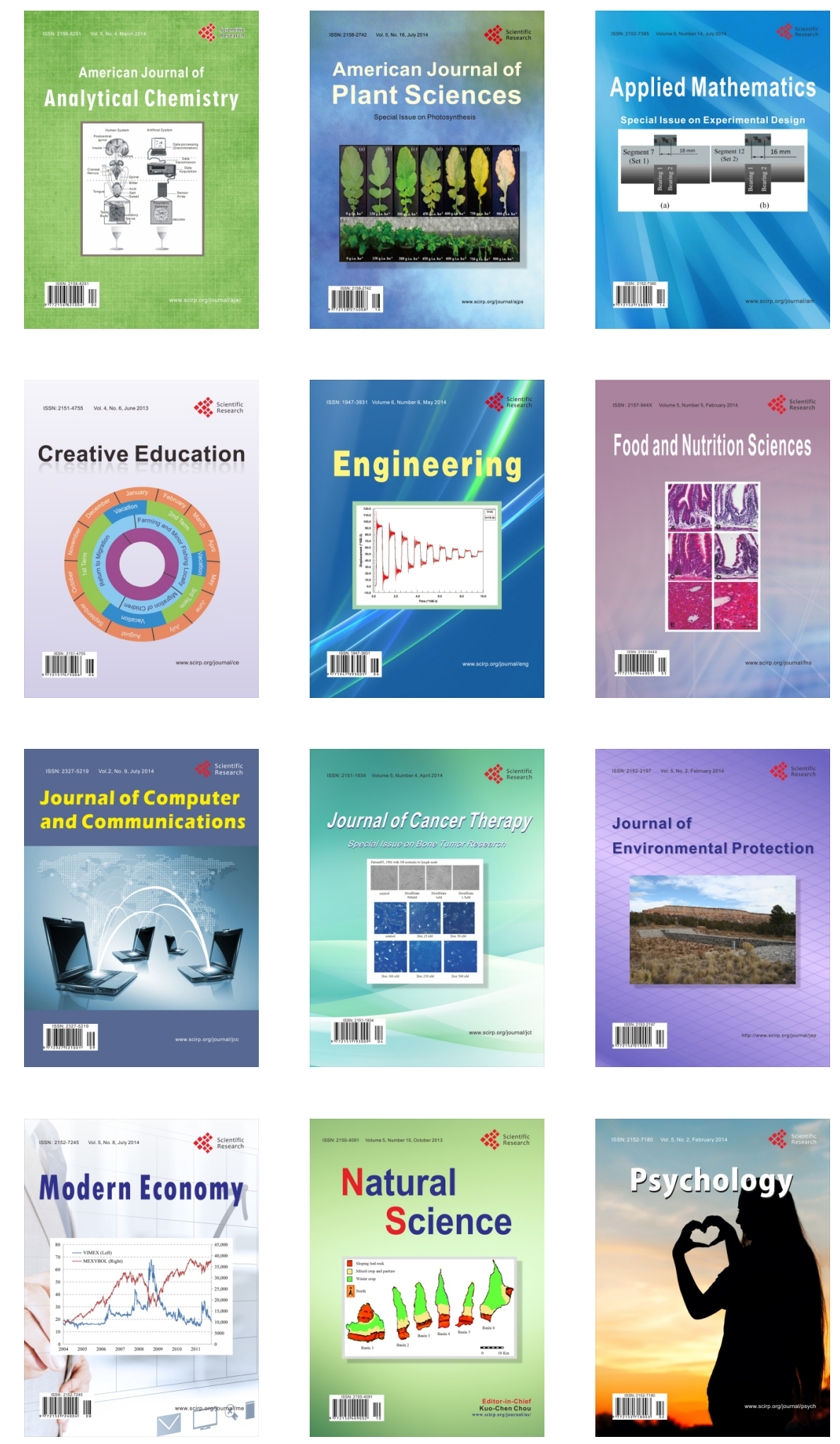